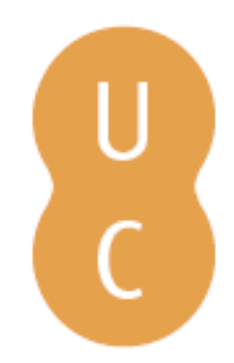

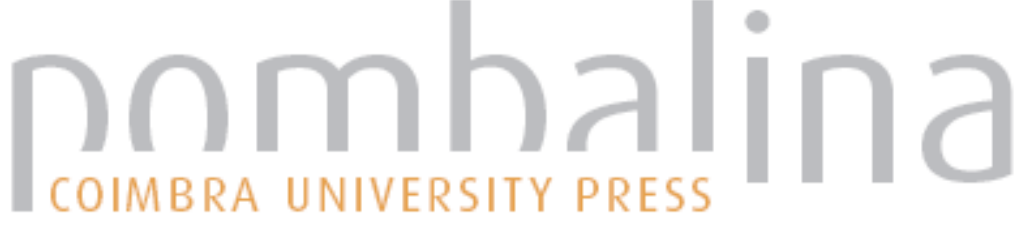

\section{Bucolismo no teatro novilatino português}

Autor(es): $\quad$ Pinho, Sebastião Tavares de

Publicado por: Imprensa da Universidade de Coimbra

URL

persistente: URI:http://hdl.handle.net/10316.2/32351

DOI: $\quad$ DOI:http://dx.doi.org/10.14195/978-989-26-0482-4_10

Accessed : $\quad$ 26-Apr-2023 15:28:11

A navegação consulta e descarregamento dos títulos inseridos nas Bibliotecas Digitais UC Digitalis, UC Pombalina e UC Impactum, pressupõem a aceitação plena e sem reservas dos Termos e Condições de Uso destas Bibliotecas Digitais, disponíveis em https://digitalis.uc.pt/pt-pt/termos.

Conforme exposto nos referidos Termos e Condições de Uso, o descarregamento de títulos de acesso restrito requer uma licença válida de autorização devendo o utilizador aceder ao(s) documento(s) a partir de um endereço de IP da instituição detentora da supramencionada licença.

Ao utilizador é apenas permitido o descarregamento para uso pessoal, pelo que o emprego do(s) título(s) descarregado(s) para outro fim, designadamente comercial, carece de autorização do respetivo autor ou editor da obra.

Na medida em que todas as obras da UC Digitalis se encontram protegidas pelo Código do Direito de Autor e Direitos Conexos e demais legislação aplicável, toda a cópia, parcial ou total, deste documento, nos casos em que é legalmente admitida, deverá conter ou fazer-se acompanhar por este aviso.

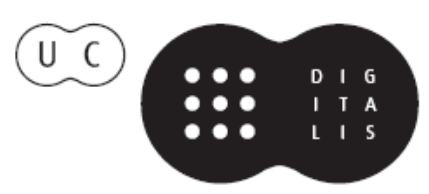


Sebastiāo Tavares de Pinho

Coordenação

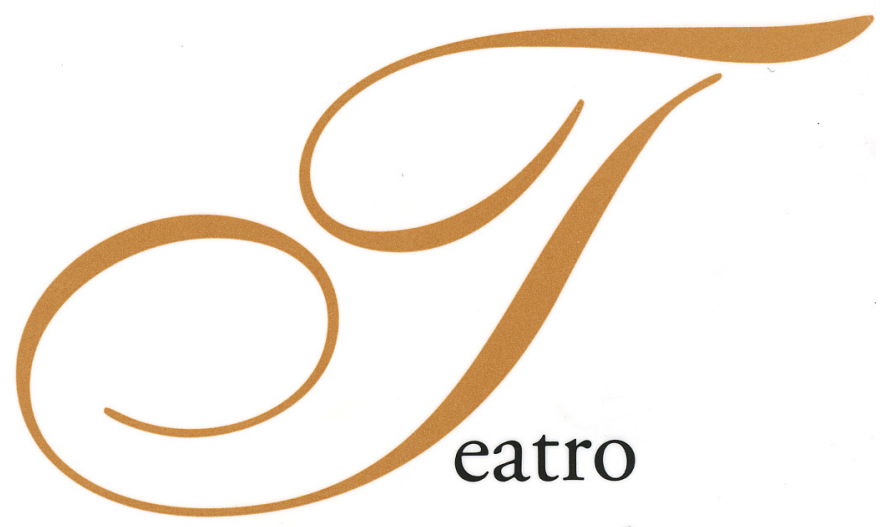

Neolatino em Portugal

no Contexto da Europa

450 Anos

de Diogo de Teive

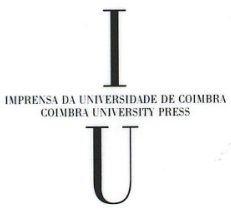

- COIMBRA 2006 
(Página deixada propositadamente em branco) 
C

U

M

E

$\mathrm{N}$

T

0

S

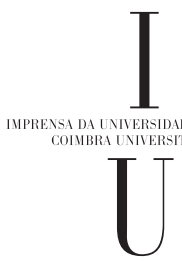




\section{COORDENAÇÃO EDITORIAL}

Imprensa da Universidade de Coimbra

URL: http//www.imp.uc.pt

\section{CONCEPÇÃo GRÁFICA}

António Barros

PRÉ-IMPRESSÃo

António Resende

Imprensa da Universidade de Coimbra

EXECUÇÃo GRÁFICA

SerSilito - Maia

ISBN

$972-8704-75-5$

DEPÓSITO LEGAL

(C) Junho 2006, Imprensa da Universidade de Coimbra

OBRA PUBLICADA COM O FINANCIAMENTO DE:

Centro de Estudos Clássicos e Humanísticos

FCT Fundação para a Ciência e a Tecnologia

MINISTÉRIO DA CIÊNCIA, TECNOLOGIA E ENSINO SUPERIOR Portugal

OBRA PUBLICADA COM O APOIO DE:

FCT: Fundação para a Ciência e Tecnologia • Ministério da Ciência e do Ensino Superior Apoio do Programa Operacional para a Ciência, Tecnologia, Inovação do III Quadro Comunitário de Apoio 
O TEATRO NeOlatino EM PORTUGal NO CONTEXTO DA EUROPA

450 AnOs DE DIOGO DE TEIVE 
(Página deixada propositadamente em branco) 
Sebastião Tavares de Pinho

Universidade de Coimbra

\section{BUCOLISMO NO TEATRO NOVILATINO PORTUGUÊS}

Uma das características da poesia bucólica clássica, reconhecida desde longa tradição, é a sua "vis dramatica", a sua capacidade de ser representada em palco, como aconteceu em particular com as Éclogas de Virgílio, a fonte mais abundante e mais directa do bucolismo moderno.

São conhecidos os testemunhos dos primeiros biógrafos do Mantuano, entre os quais se destaca o conhecido Sérvio Mário Honorato, que no comentário à obra virgiliana distingue as Bucólicas das Geórgias e da Eneida, classificando as primeiras como um género «humilde em razão do conteúdo e das personagens, uma vez que estas são, aqui, personagens campestres: bumile, pro qualitate negotiorum et personarum, nam personae bic rusticae sunt. E o mesmo comentador acentua a preocupação do Virgílio bucólico em respeitar a verosimilhança, como os dramaturgos, levando a pensar que as suas éclogas são afinal modelos de poesia comparáveis a uma espécie de mimos lírico-dramáticos. É ainda o mesmo Sérvio que, no comentário à Bucólica VI, dá notícia de ela ter sido lida em público pelo próprio Virgílio com grande aplauso dos espectadores, e também cantada no teatro pela meretriz Citéris na presença e para espanto de Cícero, que quis saber quem era aquele jovem autor. Do mesmo modo, na Vita do biógrafo Donato, se recorda que Virgílio tivera tal sucesso com a edição das Bucólicas, que estas eram, até, frequentemente apresentadas em cena por cantores (Bucolica eo successu edidit, ut in scaena quoque per cantores crebro pronuntiarentur), 
testemunho confirmado quase ipsis verbis também por Filargírio na sua biografia de Virgílio.

Não admira que a poesia bucólica virgiliana tivesse sido posta em cena mais ou menos teatral, porquanto a sua feição dramática manifesta-se, à evidência, em muitos dos principais aspectos da sua composição. Entre eles ressaltam a dimensão de espaço e tempo, os cenários e o décor ambiental; a coreografia do movimento e da música com seus ritmos diversos em função do variado sistema estrófico, por vezes acompanhado de refrão; a estrutura dialógica externa, no caso do canto à desgarrada — o famoso canto amebeu - e mesmo no diálogo interno, manifesto nos monólogos; bem como as justas e certames poéticos entre os pastores, no cenário dinâmico de um tribunal; e enfim o ambiente rústico e todas as formas do seu travesti que definem a poesia lírica pastoril e que se enquadram no vasto campo do disfarce, igualmente presente nas várias modalidades do teatro.

Compreende-se, pois, a razão por que o teatro moderno recorreu com frequência ao disfarce da roupagem pastoril para dar corpo dramático a muitas das suas peças. Isso verifica-se, como é sabido, em grande parte das literaturas europeias de língua vernácula.

Era, também, natural que a inclusão da poesia pastoril se tivesse verificado no teatro neolatino em geral e, muito em particular e de uma forma sistemática, na produção dramática jesuítica, designadamente em Portugal. Em primeiro lugar pelo carácter dramatúrgico do bucolismo greco-latino, sobretudo o virgiliano, como vimos, e em segundo lugar porque os dramaturgos portugueses de línguas vernáculas também desde há décadas o praticavam de uma forma assumida e com grande efeito cénico. O caso de Gil Vicente é paradigmático, pois, de entre as suas 40 peças, 17 são textos de estrutura basicamente pastoril ou incluem figuras de pastores ou pastoras. Quanto ao teatro desenvolvido pelos jesuítas, nos seus colégios, especialmente em Coimbra, convém recordar que o público desta cidade estava afeito ao teatro vicentino, porquanto algumas das suas peças foram aqui representadas, por exemplo em 1526 e 1527. E algumas tiveram mesmo 
por objecto principal do seu conteúdo a própria cidade universitária, haja em vista, por exemplo, a Comédia sobre a divisa da cidade de Coimbra.

O teatro neolatino surge em Portugal, como é sabido, com a reorganização dos estudos clássicos à sombra da Universidade Portuguesa, reformada e definitivamente estabelecida em Coimbra em 1537, e em particular com a fundação, em 1548, do Real Colégio das Artes aqui instituído, cujo corpo docente incluía dramaturgos já consagrados vindos do Colégio da Guiena, em Bordéus, a convite e na companhia do seu director André de Gouveia, que veio exercer as mesmas funções no novo colégio coimbrão. Entre eles contavam-se os nomes do francês Guillaume de Guérente e do escocês Jorge Buchanan, cujas tragédias latinas haviam feito grande sucesso em Bordéus e impressionaram o jovem aluno Montaigne, segundo o seu testemunho deixado no capítulo XXV do Livro I dos seus Essais, quando afirma, começando por citar, curiosamente, um verso da Bucólica VIII de Virgílio:

"Alter ab undecimo tum me uix ceperat annus, j'ai soutenu les premiers personnages ez tragédies latines de Bucanan, de Guerente et de Muret, qui se représentaient en notre collège de Guienne avec dignité. En cela, Andreas Goveanus, notre principal, comme en toutes autres parties de sa charge, fut sans comparaison le plus grand principal de France [...].

Este passo, por um lado, revela a prática habitual e o interesse que o teatro tinha na pedagogia das instituições de formação e ensino do século XVI, e, por outra parte, destaca o grande prestígio do humanista português, André de Gouveia, que logo depois veio a ser encarregado por D. João III de organizar o grande colégio público e de fundação régia em Coimbra, o Real Colégio das Artes, do qual foi o primeiro director ou principal, como então se dizia.

Mas não sabemos se o teatro daqueles dois dramaturgos - Guérente e Buchanan - que com ele vieram para Coimbra terá sido, depois, representado também aqui, durante a sua permanência como professores do Colégio das Artes. Temos, porém, o exemplo do português seu compa- 
nheiro e seguidor, Diogo de Teive, a quem se deve uma notável actividade dramatúrgica de mestre, autor e encenador, da qual se conservou, pelo menos, a conhecida Tragoedia, Quae inscribitur, Ioannes Princeps (a Tragédia intitulada Príncipe João), cujos 450 anos se pretendem evocar com a realização deste colóquio.

Desta obra e do título e assunto das peças bíblicas teivianas que se perderam — David e Judith —, parece podermos concluir que a poesia bucólica não terá sido contemplada na sua estrutura. A ser assim, teremos de esperar pelo trabalho pedagógico dos Jesuítas, que pouco depois se instalaram nos meios culturais portugueses, especialmente em Coimbra, Lisboa e Évora, para detectarmos a presença do teatro neolatino pastoril em Portugal.

Como fontes de informação temos basicamente a correspondência epistolar e os relatórios da época, os estudos modernos já realizados e muito em particular os textos manuscritos da produção dramática jesuítica. Neste domínio, os responsáveis pela formação intelectual, pedagógica, científica e literária dos colégios da Companhia, instalados em Portugal desde 1542, tiveram a laudabilíssima preocupação de copiar e guardar em arquivo a produção literária dos seus mestres e colaboradores composta por ocasião e motivo de variadas circunstâncias e actividades, como a abertura do ano escolar, a concessão de graus, a atribuição de prémios, as celebrações festivas sobretudo da Rainha Santa Isabel (no caso do Colégio de Coimbra), a visita de alguma notável personalidade e outros acontecimentos sociais ou académicos.

No caso do primeiro colégio dos jesuítas, em Coimbra, e do Colégio das Artes, que a partir de 1555 passou também para a sua direcção, grande parte de tal produção ficou sistemática e sucessivamente arquivada, dando origem a pelo menos seis grossos códices manuscritos de que se conhecem até agora os tomos I e II, e V e VI, e que ostentam o título quase comum de Rerum scholasticarum, quae a patribus, ac fratribus huius Conimbricensis Collegii scriptae sunt, Tomus primus, e Rerum scholasticarum quae a patribus ac fratribus buius Conimbricensis Colegii scriptae sunt, Tomus 
$2^{u s}$, ou Rerum scholasticarum quae a Patribus huius Conimbricensis Colegii scriptae sunt, Tomus quintus; ou, ainda, Thesaurus rerum scholasticarum, quae a Patribus, ac Fratribus Collegii Conimbricensis scriptae sunt, ab Anno Domini 1631. Tomus $6^{u s}$.

São sobretudo estes códices e também algumas cópias miscelânicas relativas quer aos referidos colégios de Coimbra, quer de Lisboa ou de Évora, que contêm a principal informação manuscrita sobre o conteúdo da produção literária neolatina (e mesmo grega e hebraica) dos jesuítas em Portugal. Tal produção abrange as áreas da poesia, em variados modelos, da oratória em grandes orações de sapiência ou em simples oratiunculae de curta dimensão, bem como do teatro, tanto em peças de ampla estrutura, como sob a forma de pequenas declamações, em monólogos ou em diálogos.

É aqui que encontramos o teatro bucólico neolatino de que pretendemos falar. Este aparece umas vezes disfarçado em textos que não se apresentam como formalmente pastoris mas que têm conteúdo bucólico no seu todo ou em parte; outras vezes trata-se de peças de modelo assumidamente pastoril, confirmado com o título de Ecloga.

As primeiras notícias da representação de uma peça teatral com esse título aparece, tanto quanto sabemos, numa carta quadrimestral do Padre Frutuoso André datada de 31 de Dezembro de 1555 com um relatório acerca da cerimónia inaugural do Colégio de Évora em 1 de Outubro daquele ano, precisamente na data em que em Coimbra a mesma Companhia de Jesus assumia a direcção do Real Colégio das Artes, passando assim a dirigir não apenas o seu colégio particular de Coimbra e primeiro da Companhia mas também o maior colégio público do País.

Na descrição da cerimónia de Évora, o P. Frutuoso fala dos muitos discursos académicos ornamentados com as variadas cores da literatura, da composição de epigramas escritos por mestres e alunos e dedicados à Virgem e a outros santos, bem como ao cardeal-infante D. Henrique, num total de cerca de 1.800 versos, afixados nas colunas e paredes; e também da representação de um certo diálogo escrito em prosa, cheia de humor e 
elegância e que causou nos ouvintes o maior deleite. À tarde «Foi representada uma écloga composta em hexâmetros, de conteúdo adequado e claro, e mesmo em versos de grande beleza e musicalidade e adornada com abundância de sábios conceitos, de tal maneira que, dado o modo como foi representada pela actuação e declamação dos garotos, é inacreditável o enorme prazer que ela a todos causou" (Post hanc, ecloga quaedam acta est, carminibus bexametris conscripta, facilis et perspicua, et ipso carminibus sonitu admodum uenusta atque multis sapientibus sententiis ornata, quae puerorum actione et pronuntiatione quodam modo expressa incredibile est quantum omnibus placuerit). O relator acrescenta ainda que o cardeal-infante D. Henrique, ao ter conhecimento do facto, manifestou o desejo de a ver, e que por isso ela foi representada poucos dias depois na sua presença ( $D e$ ea igitur cum Princeps Cardinalis certior factus esset, eam se cupere audire dixit; quapropter paucis post diebus coram eo acta est) ${ }^{(1)}$.

Igual notícia se pode colher de uma carta quadrimestral do P. Diogo de Barros a respeito do Colégio de Santo Antão de Lisboa, onde, por ordem do Prefeito de Estudos, o mestre da segunda classe compôs uma écloga de Natal e a fez representar pelos seus alunos no Dia da Circuncisão, isto é, a 1 de Janeiro, no ano de 1557. A descrição do conteúdo confirma que se trata de um auto pastoril, pois nele intervêm como actores Maria e José, um anjo e quatro pastores. Tal como no caso anterior de Évora, também aqui o êxito desta Bucólica foi tão grande e tão aplaudido por gente letrada, da nobreza e da corte, que, a pedido do rei D. João III, ela foi pouco depois reposta em cena no próprio paço diante e para admiração da família real(2).

Temos ainda conhecimento de outras bucólicas neolatinas, representadas por motivo da distribuição de prémios escolares, designadamente em Évora

(1) Vd. Monumenta Historica Societatis Iesu, Litt. Quadr. IV, p. 771. Cfr. Jesús Menéndez Peláez, Los Jesuitas y el Teatro en el Siglo de Oro, Oviedo, Universidad de Oviedo, Servicio de Publicaciones, 1995 , p. 504.

(2) Vd. Monumenta Historica Societatis Iesu, Litt. Quadr. V, p. 15. Cfr. Jesús Menéndez Peláez, op. cit., p. 506, e Maria Margarida Lopes de Miranda, Miguel Venegas S. I. e o Nascimento da Tragédia Jesuítica. A Tragoedia cui nomen inditum Achabus (1562). Edição crítica, tradução, comentário e notas, Coimbra, 2002, p. 31 (tese dactilografada). 
(1561), em Braga (1564), em Bragança (1571), entre outras. Mas em todos estes casos, como nos dois anteriores de Évora e Lisboa, dos quais existe apenas alguma notícia acerca do tema ou das circunstâncias de representação, tudo o resto - título, conteúdo e texto - continua desconhecido.

Todavia, para a apreciação objectiva do teatro pastoril neolatino em Portugal temos felizmente o abundante acervo dos códices manuscritos atrás referidos, onde podemos encontrar mais de uma dezena de obras dramáticas que ostentam, mais ou menos formalmente, a sua marca bucólica.

Entre as de maior dimensão e de estrutura mais orgânica, incluindo a divisão em actos, encontram-se a Egloga quae inscribitur Gerion da autoria de Lucas Pereira e representada em Coimbra em 1612; a écloga Marsyas, de João da Rocha, talvez encenada também em Coimbra, cerca de 1616; o David Pastor, de Domingos Teixeira, em 1618 em Coimbra; a «Declamatio» Dares et Entellus, de Pedro de Vasconcelos, Coimbra, 1629; e Eustachius Venator, de André Fernandes, representada em Évora em 1635. O estudo destas cinco peças é fundamental para a apreciação do bucolismo no teatro neolatino em Portugal. Mas não o vamos fazer aqui, sem sequer sumariamente, porquanto já foram estudadas por Claude-Henri Frèches num extenso capítulo da sua tese sobre o teatro neolatino em Portugal(3) e porque sobre elas já tive também ocasião de falar em outra ocasião ${ }^{(4)}$. Aqui tratarei apenas de outras composições dramáticas igualmente bucólicas mas de menor dimensão e que ainda não foram objecto de um estudo em particular.

Um dos primeiros exemplos é a de Manuel Pimenta que foi posta em cena em Coimbra em 1564 e que tem por título simplesmente Dialogus in praemia, que a identifica como sendo destinada à cerimónia de entrega de prémios académicos. Apesar de não se intitular como "Écloga», ao contrário do que acontece com outros exemplos que veremos, a inspiração do

(3) Vd. Le théâtre néo-latin au Portugal (1550-1745), Paris-Lisbonne, 1964, pp. 447-498.

(4) Vd. Sebastião Tavares de Pinho, "Literatura humanística inédita do Colégio das Artes da Universidade de Coimbra no século XVI", in Universidade(s), História, Memórias, Perspectivas, Actas do Congresso "História da Universidade» no $7^{\circ}$ Centenário da sua Fundação, Coimbra, 1991, vol. 4, pp. 67-86, e «O Colégio das Artes da Universidade de Coimbra, agente da tradição clássica no início do século XVII», Biblos 68 (Coimbra, 1992) 49-76. 
bucolismo clássico manifesta-se desde logo pela presença de conhecidos pastores virgilianos no elenco dos seus actores, como "Palaemon", ou forjados na onomástica do Mantuano, como «Maenalus». Trata-se de um diálogo de 444 versos, sendo os primeiros doze em dísticos elegíacos, equivalentes ao Prólogo, e todo o resto em hexâmetros dactílicos, em que intervêm os interlocutores Faburnus, Maenalus, Ortalus, Lycota, Palaemon e Megadorus, num certame de rivalidades poéticas e num curioso processo dinâmico de progressão dialógica crescente: primeiro o despique verifica-se entre Faburno e Ménalo (vv. 15-199); depois entre Licota e Órtalo (vv. 200-267); a seguir rivalizam estes quatro em simultâneo (vv. 268-378); depois (vv. 379-425) junta-se-lhes o juiz Palémon, o mesmo que na Bucólica III de Virgílio preside ao concurso entre Menalcas e Dametas; por fim cantam todos juntamente com Megadoro, a conhecida figura plautina, que aqui também serve para acentuar a ideia de que este poema do jesuíta Manuel Pimenta tem estrutura intencionalmente dramática.

Além dos nomes de pastores, são muitas as outras marcas de evocação virgiliana que percorrem este Diálogo no campo da linguagem, das imagens e de outros variados estilemas. E nem falta, a terminar, o quadro do entardecer (vv. 440-444), que recolhe elementos das Bucólicas I, 83; II, 67 e III, 108-111, do Mantuano:

Levantai-vos rapazes: já nos montes se prolongam as sombras Já o Héspero orvalhado mostra seus ardentes luzeiros.

Fechai agora, meus rapazes, fechai agora os touros nos currais. A mim cabe-me, no tempo da bruma, pôr termo às disputas. Vivei felizes, vivei e conservai-nos na vossa lembrança.

Pimenta, 440-44:

Surgite iam, pueri, duplicant montibus umbrae

Hesperus ardentes ostendit rosidus ignis.

Claudite iam, pueri, stabulis iam claudite tauros.

Ipse ego brumali compono tempore lites

Viuite felices, memores et uiuite nostri. 
Virgílio,

B. I, 83:

Maioresque cadunt altis de montibus umbrae.

B. II, 67:

Et sol crescentis decedens duplicat umbras.

B. III,108-111:

Non nostrum inter uos tantas componere lites;

Et uitula tu dignus et hic, et quisquis amores

Aut metuet dulces, aut experietur amaros.

Claudite iam riuos, pueri: sat prata biberunt.

E para prova de que se trata de uma bucólica levada ao tablado teatral, temos as próprias palavras do clássico Prólogo, que ocupa os primeiros 14 versos, compostos em dísticos elegíacos, para o distinguir do diálogo da peça propriamente dita, toda escrita em hexâmetros, e que, no exercício da sua tradicional função, assim adverte o auditório, personificado nos padres-mestres e nos jovens estudantes do Colégio de Coimbra:

Augusta grauitate, patres, conuertite mentes,

Atque Castaliis gnaua iumenta choris,

Non ueniet fuso lacrimosa tragoedia uelo,

Callida nec uafris comica turba Getis.

Carmina bucolico pecudum canet ore magister,

Vitat inhumani rusticus ora lupi.

Illum Musa leuat terra sublimis, at ille

Exuit hirsutis pectora uelleribus.

Ortalus urbanae memorat mala commoda uitae,

Sedulus agrestes laudat arator opes,

Gramine considet Iudex frondente Palaemon,

Pastor inaequali dum canit ore modos.

Rustica iam ueniet pubes; aduertite undique

Auraque tentatum fausta secundet iter.

Prestai atenção, padres, com augusta gravidade,

E vós, ó juventude industriosa nos coros de Castália.

Não é a lacrimosa tragédia que, de vela solta, vai aparecer aqui,

Nem a malta cómica treinada nas malandrices getas. 
Aqui o maioral dos rebanhos entoará canções com sua bucólica voz,

O camponês foge da boca do desumano lobo.

Àquele, a excelsa Musa o levanta do chão; e este

Desnuda seu peito dos hirsutos velos.

Órtalo relembra as maléficas comodidades da vida urbana,

O dedicado lavrador louva os recursos do campo.

No frondente relvado toma assento o juiz Palémon

Enquanto o pastor entoa seus versos em voz alternada.

Em breve chegará a juventude campestre. Reparai à vossa volta,

E que uma aura propícia favoreça o caminho já tentado.

No mesmo ano de 1564 e também em Coimbra, é encenada uma peça da autoria do P. Júlio Fácio ${ }^{(5)}$, que se assume como uma verdadeira bucólica, porquanto ostenta o título de «Ecloga de Nataliciis Domini». É uma composição já de maiores dimensões, com 713 versos, e que apresenta uma divisão orgânica em três partes, equivalentes a três actos de uma normal estrutura dramática. Conta com um variado elenco de «interlocutores», que inclui a Sybilla Cumaea, que faz de Prologus; Meliandrus pastor senex, Corillus puer eius filius, Floricus adolescens, Axillus puer, Phylomelus grandis natu, Faustulus adolescens, Zephyreus grandis natu, Lycota iumenis, todos pastores; um Angelus nuntius, juntamente com o Chorus Angelorum e um

\section{Chorus Prophetarum.}

Não é apenas o título desta composição e a personificação de pastores assumida pela grande maioria destes interlocutores que lhe concedem um carácter bucólico. É sobretudo o conteúdo ideológico e formal do seu texto que o confirma, pelo uso dos mesmos recursos literários da poesia bucólica clássica, sobretudo virgiliana. É a referência à vida dos pastores e à paisagem e flora do seu ambiente, expressos em vocabulário, sintagmas e estilemas característicos da literatura pastoril.

Intervém em primeiro lugar a Sibila de Cumas, que expõe num Prólogo de 53 hexâmetros a ideia central desta bucólica, anunciando o nascimento

(5) Sobre este jesuíta (Fácio? Fassio? ou Fazio), vd. Francisco Rodrigues, S. J., História da Companbia de Jesus na Assistência de Portugal, Porto, 1931, Tomo I, Volume I, p. 521, nota 1. 
de um salvador, que virá restabelecer a nova ordem de um novo século de felicidade e paz, glosando e adaptando aos conceitos cristãos o conteúdo e as formas literárias do bucolismo do Mantuano em geral, e sobretudo o texto e a mensagem da sua famosa Bucólica Messiânica. O autor não hesita em chamar "Saturnia regna" à nova idade regenerada pela vinda de Cristo, nem em designar o Menino-Deus da era cristã como a «cara descendência do Tonante», num contexto (vv. 19-26) directamente decalcado naquela Écloga IV virgiliana:

Scilicet haec aetas, haec sunt Saturnia regna,

Qua quondam populis cecini uentura futuris.

Ter felix nobis aetas, qua cara Tonantis

Progenies caelo tandem demissa supremo

Adueniet nostris finem latura ruinis,

Qua duce Tartareis serpens imbuta uenenis

Occidet, et ueteris subito contagia culpae

Irrita, praeclusi reserabunt limen Olympi.

É claro que é esta a idade, são estes os reinos de Saturno

Que outrora anunciei que haviam de vir para os povos futuros.

Três vezes feliz para nós a idade em que a cara progénie

Do Tonante, finalmente enviada do Céu supremo,

Há-de chegar para pôr fim à nossa ruína,

E sob cujo império a serpente embebida nos venenos do Tártaro,

há-de cair morta, e, subitamente, os contágios da antiga culpa, anulados, hão-de abrir as portas do encerrado Olimpo.

A primeira parte da peça (Pars Prima, vv. 54-221) contém o diálogo dos pastores Meliandro, Corilo e Flórico, que desenvolvem o tema anunciado no prólogo sibilino, glosando e adaptando à circunstância da moderna celebração cristã, muito do conteúdo dos diálogos dos pastores de Virgílio, designadamente o confronto das suas preferências sobre os dons da natureza, a troca de presentes e o despique da sua qualidade. O diálogo é entrecortado de partes cantadas por todos em simultâneo. 
Na segunda parte (vv. 222-469) intervêm, além do velho pastor Meliandro, os outros pastores Filomelo, Zefireu, Fáustulo e Axilo, em texto umas vezes declamado, outras cantado, quer em diálogo, quer em monólogo, onde continuam os tópicos do bucolismo clássico em que não falta a evocação de outros pastores como Menalcas e Amintas. Um dos temas desenvolvidos é o da exaltação da modesta vida do campo em contraste com a complexidade do bulício urbano, expressa num longo e belo canto alternado que Meliandro, o pastor mais velho, convida os mais jovens a entoar enquanto ele os acompanha com sua flauta e cujo sentido se resume neste refrão sucessivamente repetido (vv. 295-324):

O felix pastor uicinae nescius urbis, O felix paucis pastorum uita capellis.

Oh, feliz o pastor que não conhece a vizinha cidade!

Oh, feliz a vida dos pastores com um pequeno rebanho de cabras!

Meliandro dá por findo este tema, ordenando a seus companheiros:

Cantatum satis est, alio iam uertite mentes

Nam defessa meo delabitur ore cicuta.

Basta de cantar, voltai agora vossas mentes para outro lado, Que a minha flauta, cansada, já da boca me descai.

A terminar a Secunda Pars intervém o Coro dos Profetas em versos glicónios (glosando o poema litúrgico "Rorate caeli desuper, etc." segundo a didascália do manuscrito), seguido do Anjo mensageiro, que anuncia o nascimento de Cristo, e do Coro da Anjos em versos anapestos e adónios, em contraste com todo o resto da estrutura métrica dactílica desta Écloga.

Na terceira e última parte (vv. 470-705) intervêm todos os oito pastores num diálogo em que expressam a sua alegria pela notícia do nascimento do Deus-Menino, naquela noite em que uma estranha luz veio iluminar as trevas. A convite do velho Meliandro todos os oito pastores se dirigem em cortejo para o presépio, cantando um poema compassado por este refrão: 
Visite siderei cunabula, visite, Regis

Ferteque uimineis redolentia dona canistris.

Venham ver, venham, o berço do Rei sideral,

E trazei-lhe dons perfumados, em vossas cestas de vime.

Chegados ao presépio preparam-se para adorar o Deus-Infante, declamando cada um o seu hino pessoal e apresentando-lhe suas oferendas. Tal como acontece com o pastor Menalcas da Bucólica V, 4, de Virgílio, também aqui é dada prioridade a Meliandro por ser o mais velho, conforme adverte o jovem pastor Licota:

Tu Meliandre graui cum sis maturior aeuo Accede, et puero senior da munera primus

Tu, Meliandro, pois que és mais maduro em idade e ponderação, Avança e, como mais velho, sê o primeiro a oferecer teus presentes [ao Menino.

Os pastores desdobram-se em rivalizar com seus cantos, em que se cruzam altos pensamentos teológicos dos pastores mais velhos sobre o mistério da incarnação com expressões de poética e ingénua graciosidade, como esta com que o pequenino pastor Axilo se dirige ao Menino-Deus:

O mihi formosis infans formosior agnis,

Pulcrior haediculis, dulcique iucundior uua.

Ó infante para mim mais formoso que os formosos cordeiros, Mais belo que os cabritinhos e mais jucundo que a doce uva.

A écloga termina com um típico quadro do anoitecer, de sabor virgiliano, (... iam proxima uagas nox duplicat umbras) seguido de um cântico final entoado e acompanhado pela flauta de dois tubos de Meliandro e pela dança dos restantes pastores, que fecha com a exaltação da vida pastoril e campestre e da nova idade regenerada pela incarnação do Verbo, comparável à mítica idade de ouro dos tempos de Saturno: 
En amat in siluis infans habitare remotis.

Nemo mibi urbanas nunc, o nunc, iactet honores!

Rustica simplicitas, tenuisque triumphat egestas.

Nemo mibi urbanas nunc, o nunc, iactet honores!

Hic uiget alma quies, uiget hic secura uoluptas.

O felix aetas, felicia gaudia ruris!

o felix aetas rutilo formosior auro!

Eis que o Menino deseja habitar nas florestas remotas.

Ninguém me venha agora, oh! agora, com honras urbanas.

Triunfa a rústica simplicidade e a frugal privação.

Ninguém me venha agora, oh! agora, com honras urbanas.

Aqui reina a pura tranquilidade, reina o sossegado prazer.

Ninguém me venha agora, oh! agora, com honras urbanas.

Ó feliz idade, felizes alegrias do campo,

Ó feliz idade mais formosa que o ouro esplendoroso.

Pelo ano de 1567, de novo Manuel Pimenta escreve outra composição pastoril, igualmente representada em Coimbra, a que dá o nome de Aepolus

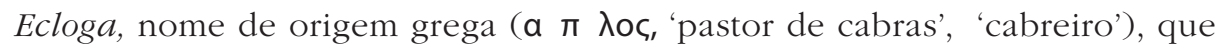
evoca o bucolismo siciliano de Teócrito. Trata-se de um diálogo compacto de cerca de 550 hexâmetros, precedido de um prólogo de 13 dísticos elegíacos, no qual cinco pastores confrontam seus amores, paixões, rivalidades e sonhos sob o disfarce da vida e das preocupações da pastorícia, para gáudio e divertimento dos espectadores. O prólogo é encarnado pela figura do Rumor, o Boato, cuja autodescrição com que ele se apresenta acumula várias reminiscências virgilianas do desenho da Fama, do canto quarto da Eneida. Diz o Rumor de Manuel Pimenta:

Si quis centum oculos cinctum fulgentibus Argum

Me putat, aspectu fallitur ille meo,

Nexa uidet quicumque meis talaria plantis,

Me si Mercurium credulus esse putat.

Rumor ego Hesperiis, et Rumor notus Eois,

Rumor ad hibernos cognitus usque Getas;

Tot mibi sunt aures, tot in omni corpore plumae,

Lumina pro pluma uersicolore latent. 
Se alguém me julga um Argo, de cem olhos fulgurantes

Cingido, esse co'a minha aparência se engana,

E quem quer que veja meus artelhos atados nas plantas dos pés,

Se credulamente julga que eu sou Mercúrio.

Eu sou o Rumor conhecido nas Hespérias, conhecido nas Auroras,

O Rumor reconhecido até pelos Getas hibernais.

Tenho tantos ouvidos quantas, em todo o corpo, as penas;

Por detrás da pluma versicolor estão escondidos meus olhos.

As outras personagens, que são os verdadeiros interlocutores, têm nomes de origem ou formação grega, como Aepolus, Comatas, Galanther, Battus e Aegon, como acontece com os pastores de Virgílio, mas com a particularidade de que, quase todos eles, com excepção de Aegon, não figuram no elenco do Mantuano, mas sim nos Idílios de Teócrito. Isto leva a concluir que o jesuíta Manuel Pimenta se terá inspirado muito provavelmente também no bucolismo greco-siciliano.

Outra particularidade desta Bucólica é a sua integração na cultura e no espaço português, porquanto os pastores, no seu longo canto amebeu de permanente disfarce, acabam por localizá-lo não apenas na dimensão topográfica da tradição greco-latina, mas no espaço e no tempo real e contemporâneo portugueses. A Arcádia geográfica de Teócrito ou a idealizada por Virgílio nas margens do Míncio, ou as regiões da mais antiga tradição clássica, dão lugar aos campos do Mondego, às lezírias do Ribatejo, às águas do Minho e às terras escarpadas do Douro, por exemplo quando o pastor Bato, fazendo eco e adaptação da Bucólica IV de Virgílio, assim responde a Épolo, ocupado nos elogios da fertilidade dos campos de Tróia e da riqueza do seu rei, num texto que é ao mesmo tempo a exaltação de Coimbra como centro de formação e cultura do Portugal de Quinhentos:

Aepole, magna canis, sed nos maiora canemus.

Cantas grandiosa matéria, Épolo, mas nós cantaremos ainda maior.

Monda ubi per campos, et roscida prata uolutus

Argutos inter uolucrum certamine cantus

Perspicuas ducit lucenti gurgite lymphas,

Ardua Castaliae posuere sedilia Musae. 
Vndique discipulos uocat in sua tecta Minerua,

Conueniunt populi uaris e partibus orbis.

Auriferi trans alta Tagi quae flumina gentes

Pinguibus aspiciunt florentia messibus arua,

Quique Tagum, Miniumque bibunt, Duriumque sonorum

Inter inaccessas uoluentem flumina rupes.

Ciuis Vlyssaea properat generosus ab urbe.

Ver ubi purpureum florentia protulit ora

Continuo pubes armis accincta Mineruae

Pieriis certamen init memorabile castris.

Lá onde o Mondego, voluteando pelos campos e prados orvalhados

Por entre o arguto canto dos pássaros em desafio,

Conduz suas águas transparentes em cintilante remoinho,

Colocaram as Musas de Castália seu altaneiro assento.

De toda a parte, para sua casa, chama seus discípulos Minerva,

Aí convergem os povos de variadas partes do orbe.

As gentes que, para lá das fundas correntes do aurífero Tejo,

Contemplam os campos florescentes de nutridas cearas,

E os que bebem as águas do mesmo Tejo, do Minho e do Douro sonoro

Que suas torrentes revolve por entre inacessíveis escarpas.

Apressa-se o nobre cidadão da Ulisseia Urbe.

Mal a primavera de púrpura ostenta seu rosto em flor

Logo a juventude, cingida co'as armas de Minerva,

Inicia o memorável combate dos acampamentos das Piérides.

Por vezes, os textos de carácter pastoril do teatro neolatino português são de muito menor dimensão e apresentam, naturalmente, também menor número de interlocutores, como acontece com a Ecloga in Natali Virginis Augustissimae, composta pelo jesuíta António de Morais provavelmente na viragem do século XVI para o XVII e que consta de um dos tomos dos supracitados manuscritos do Colégio de Coimbra(6).

(6) Vd. Arquivo Nacional da Torre do Tombo, Ms. 1963, Thesaurus rerum scholasticarum, quae a Patribus, ac Fratribus Collegii Conimbricensis scriptae sunt, ad Anno Domini 1631. Tomus $s^{u s}$, fls. 104v-105v. Sobre este códice, vd. o nosso recente estudo «Um códice latino da literatura jesuítica quase desconhecido: o Cód. 1963 da Livraria dos Manuscritos dos ANTT", Humanitas 57 (Coimbra, 2005) 351-382. 
Trata-se de uma composição de apenas 45 versos, com as personagens bíblicas de José — o jovem que viria a ser o pai putativo de Jesus - e do rei David, ambos na figura de pastores dialogando acerca do nascimento da Virgem Maria, numa junção anacrónica de gerações que denuncia desde logo o disfarce característico da poesia bucólica.

O enredo começa com um encontro casual entre os dois pegureiros, ao estilo bucólico virgiliano, quando, ao raiar da madrugada, o pastor José conduzia o seu rebanho para as pastagens paternas e lhe aparece o pastor David, que o saúda, e logo os dois se dirigem para as aprazíveis margens do rio Jordão (vv. 1-7). À pergunta de José sobre as últimas novidades da cidade, David traz a notícia do nascimento de uma filha de Joaquim, aquela que, oriunda do próprio ramo de David, viria a ser um dia a esposa do seu companheiro cénico (vv. 8-12). José recorda agora que, afinal, os seus cordeiros, "com seus trémulos balidos" (tremulis balatibus, v. 13), e todo o rebanho sentiram e anunciaram esse singular nascimento, revelando assim o carácter da sua predestinação divina; e convida o seu amigo a preparar as flautas e a iniciar um canto de desgarrada - o canto amebeu das Bucólicas de Virgílio - para tecer os louvores daquela santa Virgem (vv. 13-17). David responde (vv.18-23), apontando o novo astro que surgiu no céu - o astro da Virgem, que enche de alegria todo o ambiente da natureza pastoril e cuja formosura de corpo e alma superam o perfume das flores e a brancura da neve. A sua beleza vence a «áurea [estrela]», isto é, a própria Lua ou Febe, a irmã de Apolo, como reza a mitologia e os poetas repetem, entre os quais se conta Virgílio (vd. Geórgicas, 1, 431: "aurea Phoebe»), e como ela vem expressamente identificada (Phoebe) em nota marginal do manuscrito desta Écloga renascentista.

O pastor José continua o despique poético felicitando os pais que tal Filha geraram, invocando de forma implícita o famoso casal bíblico de São Joaquim (aliás explicitamente mencionado no começo do poema, v. 8) e Santa Ana, e convida o seu rival cantor a atapetar o chão com rosas, lírios 
e ramos de oliveira, para celebrar o anunciado nascimento desta "Áurea Virgem» (vv. 24-30).

David, o rei-pastor, reporta a figura desta Virgem às antigas profecias dos textos messiânicos, salientando a sua função medianeira no plano salvífico de Cristo e recorrendo, para isso, aos símbolos de salvação que acompanharam a história do povo judeu do Antigo Testamento: ela é a flor do tronco de Jessé, donde provém a genealogia de Jesus; é a cestinha que salvou Moisés nas águas do Nilo (vv. 31-35). José continua esta linguagem figurativa, fazendo identificar a mesma Virgem com o velo que apareceu a Gedeão como sinal de vitória sobre os madianitas; com a prodigiosa vara de Aarão que possibilitou a Moisés a libertação do seu povo do Egipto; com o arco íris que assinalou a aliança de Deus com Noé e seu povo após o Dilúvio; enfim, ela é a escada de Jacob e «a cândida nuvem em cujo manto de ouro se escondeu o próprio Deus» (vv. 35-40).

O carácter bucólico desta cena dialogada, que está, aliás, assumido no seu próprio título, é, ainda, confirmado pelo clássico quadro do entardecer com que ela termina e em que David evoca o lento declinar do sol e o inverso alongar as sombras que deslizam do alto dos montes, como acontece nas composições virgilianas (vv. 41-45).

É curioso notar que este diálogo constitui uma espécie de "Anunciação" no masculino, isto é, a notícia dada pelo rei David da chegada de uma virgem prenunciada pelos profetas e destinada ao matrimónio do futuro pai putativo de Jesus.

Finalmente, e à maneira também de algumas bucólicas do Mantuano, acresce a presença de refrães que se repetem ao longo do poema, marcam o ritmo musical e coreográfico do canto amebeu e acentuam algumas das ideias do seu conteúdo, designadamente a metáfora que faz identificar a Virgem Maria recém-nascida com uma nova Aurora de luz anunciadora do Cristianismo, como se pode ver no próprio texto, que a seguir transcrevemos na íntegra, acompanhado de uma proposta de tradução (o destaque, a negro, dos refrães é nosso): 


\section{AECLOGA IN NATALI VIRGINIS AVGVSTISSIMAE}

Pastores: Ioseph et Dauid

Cum patrias ductaret oues ad pascua Ioseph

Constitit obscuroque attolens lumina caelo,

"Exsere", ait, "nitidos, o Lucifer, exsere uultus".

Obuius huic Dauid dulcis - "Iosephe saltem,

5 Pastor, aue». - "Mi Dauid, aue. Quo tendis?"

DAVID

- Ad undas

Iordanis.

IOSEPH - Quam laetor! Aquas properamus ad undas.

Exsere iam nitidos, o Lucifer, exsere uultus.

Ecquid in Vrbe noui?

DAVID - Natam Ioachimus, auitae

Ille heres pietatis habet. Gratare roganti

10 Namque eodem de fonte fluit mibi sanguinis unda,

Grata unda.

IOSEPH - Optatos nimium tibi gratulor ortus.

Obrue nigrantes iam, Lucifer, obrue uultus.

Scilicet hoc nuper tremulis balatibus agni,

Hoc niuei sensere greges. Ergo illa per orbem

15 Exspectata uenit. Calamos aptemus, et almae

Virginis alterno modulemur carmine laudes.

Huc noua sidereas conuerte Aurora quadrigas.

DAVID - Ecce nouum caelo consurgit Virginis astrum,

Astrum quo pecudes gauderent fetibus, et quo

20 Grata coloratis redolerent floribus arua.

Forma index animi superat candore pruinas.

Nigra tibi collata forent tibi cederet aurea [Phoebe]

Obrue nigrantes iam, Lucifer, obrue uultus.

IOSEPH — Felices qui te talem genuere parentes,

25 Felix prole parens et felix tu quoque mater,

Num felix mater magis an pater inclitus ille?

Inclitus ille parens et felix tu quoque mater.

Huc noua sidereas conuerte Aurora quadrigas,

Sparge nouos flores et oliuis lilia mixta.

30 Alba rosa, o Dauid, nascitur aurea Virgo. 
DAVID - Hunc illum esse reor Iessaea ex arbore florem Quem super auratis requiescet Spiritus alis.

Haec illa est fiscella udo quae uimine texta Clausum Niliacis Mosem seruauit ab undis.

35 Obrue nigrantes iam, Lucifer, obrue uultus. IOSEPH - Ecce tuum uellus Gedeon, tua floribus Aron Virga nitens, cognosce tuae Noe Iridis arcum, En scalas Iacobe tuas, haec candida nubes Cuius in aurato Deus inuolutus amictu.

40 Huc noua sidereas conuerte Aurora quadrigas.

DAVID - Sed iam praecipitant altis de montibus umbrae. Coge pecus, Iosephe, ulmis dum Infantis honores Incido, accrescent ulmi, crescetis honores. Obrue nigrantes, o Lucifer, obrue uultus,

45 Aethereas posthac regat aurea uirgo quadrigas.

\section{ÉCLOGA NO NASCIMENTO DA VIRGEM AUGUSTÍSSIMA}

Pastores: JOSÉ e DAVID

Conduzia José as ovelhas aos pastos de seus pais, Quando parou e, erguendo os olhos à escuridão do céu, Diz: «Desvela, Estrela d'Alva, a tua luminosa face». Vindo ao seu encontro, o doce David lhe diz: — "Deus te salve

5 Pastor José». - «Eu te saúdo, amigo David. P’ra onde vais?» DA. - Para as águas

Do Jordão.

JO. - Quanta alegria! Vamos pressurosos às correntes das águas.

Desvela já, Estrela d'Alva, a tua luminosa face.

E que há de novo na Urbe?

DA. - Joaquim, o conhecido herdeiro

Da piedade avoenga, tem uma Filha. Congratula-te com tua pergunta,

10 Pois é da mesma fonte que flui a corrente do meu sangue, Uma grata corrente.

JO. - Muitíssimos parabéns pela tua invejável origem.

Acaba depressa, Estrela d'Alva, com a tua negra face.

Está claro que os cordeiros, com seus trémulos balidos, o sentiram; Sentiram-no os níveos rebanhos. Portanto, Ela chega esperada 
15 Através do orbe. Aprontemos as flautas e vamos tocar

Em canto alternado os louvores da santa Virgem.

Volve para aqui, ó nova Aurora, as tuas siderais quadrigas.

DA. - Eis que surge no céu o novo astro de uma Virgem,

Um astro tal, que com ele se alegram os gados com suas crias,

20 Com ele os campos exalam o perfume de suas coloridas flores.

Sua beleza, indicadora da alma, supera a candura da neve.

Tivessem sido negros teus dons, e ceder-te-ia o lugar a Áurea Estrela.

Acaba depressa, Estrela d'Alva, com a tua negra face.

JO. - Felizes dos pais que assim te geraram,

25 Feliz o pai com sua prole, e feliz também tu, ó mãe.

Acaso será mais feliz a mãe, ou aquele ínclito pai?

Feliz é aquele ínclito pai, e feliz também tu, ó mãe.

Volve para aqui, ó nova Aurora, as tuas siderais quadrigas.

Espalha, David, frescas flores e lírios misturados com ramos

30 De oliveira: como alva rosa nasce a Áurea Virgem.

DA. - Estou certo que esta é aquela flor do rebento de Jessé

Sobre a qual repousará o espírito de asas douradas.

Esta é aquela cestinha que, de vime molhado tecida,

Guardou e salvou Moisés das águas do Nilo.

35 Acaba depressa, Estrela d'Alva, com a tua negra face.

JO. - Eis o teu velo, Gedeão; eis, Aarão, a tua vara

De flores ornada; reconhece, Noé, o arco da tua Íris;

Eis, Jacob, a tua escada, esta é a cândida nuvem

Em cujo manto de ouro se escondeu o próprio Deus.

40 Volve para aqui, ó nova Aurora, as tuas siderais quadrigas.

DA. - Mas já, do alto dos montes, se precipitam as sombras.

Junta o rebanho, José; enquanto eu cravo nos olmeiros as honras

Da Infante, crescerão os olmeiros, e vós, honras, crescereis também.

Acaba depressa, Estrela d'Alva, com a tua negra face.

45 Que doravante a Áurea Virgem conduza suas etéreas quadrigas.

O bucolismo do teatro neolatino manifesta-se também, com frequência, de forma parcelar, em grandes peças, na medida em que estas contêm partes, mais ou menos amplas, com intervenção de figuras de pastores. Podemos citar, a título de exemplo, as duas obras dramáticas sobre a vida de São Paulino de Nola, contidas no Ms. 1963 do Arquivo Nacional da Torre do Tombo, já atrás referido. Uma ocupa as fls. 145r-171r e tem por título Tra- 
gicomoedia quae inscribitur Paulinus Nolae Episcopus, Conimbricae anno D[omini] 1604, e a sua autoria, registada à margem do texto manuscrito, é do jesuíta Afonso Mendes ${ }^{(7)}$, futuro patriarca da Etiópia. A outra preenche as fls. 58r-88r e, embora sem folha de rosto e por isso sem indicação de autor, poderá ser do mesmo Afonso Mendes, uma vez que trata do mesmo tema, apesar das suas grandes diferenças de texto e de estrutura.

Com efeito, no caso da Tragicomoedia, o acto IV apresenta um diálogo (fls. 160v-161v ) entre os pastores Damon, Montanus, Siluius, Glaucus e Hortulans; e, quanto à outra peça, uma boa parte do Acto V é preenchida com a actuação dos pastores Menalcas, Amintas, Meliboeus e do Pastor minimus Daphnius.

Com a apresentação e análise, ainda que sumária, destas éclogas podemos, pois, concluir reconhecendo que o bucolismo é um facto recorrente no teatro neolatino e lhe concede virtualidades acrescidas na sua função de docere et delectare. O carácter pastoril do teatro deleita e reforça a diversão, pelo exotismo e extravagância das suas personagens; favorece o veículo da crítica de costumes pela aparente ingenuidade e permanente ambiguidade. O poder instalado aceita mais facilmente a censura provinda da boca de um ingénuo pastor, porque ela parece diluir-se por detrás da sua suposta simplicidade e inocência. A feição pastoril deleita de modo particular pela variedade coreográfica da dança e da música vocal e instrumental que acompanha a poesia declamada ou cantada. Enfim, a pastorícia poética do bucolismo propicia ao teatro uma particular capacidade de docere, pela frugalidade e simplicidade de vida que simboliza.

(7) O nome de Baltasar Méndez citado como autor desta tragicomédia por Cayetano Alberto de la Barrera y Leiradi, no Catálogo bibliográfico y biográfico del teatro antigo español desde sus orígenes hasta mediados del siglo XVIII [1860], edic. facsímil, Madrid, Gredos, 1969, citado por Jesús Menéndez Peláez, Los Jesuitas y el Teatro en el Siglo de Oro, Universidad de Oviedo, 1995, p. 456, pode ser um problema de confusão de nomes. Sobre Afonso Mendes, vd. Diogo Barbosa Machado, Biblioteca Lusitana, Tomo I, Coimbra, ${ }^{2} 1965$, p. 41-45, e Baltasar Teles, História Geral da Etiópia a Alta, ou Preste João, e do que nela obraram os Padres da Companhia de Jesus [...], Coimbra, 1660, p. 696. 
(Página deixada propositadamente em branco) 


\section{Série}

\section{Documentos}

Imprensa da Universidade de Coimbra

Coimbra University Press

2006

- $\mathrm{U}$

C • 